\title{
Development, coinfection, and the syndemics of pregnancy in Sub-Saharan Africa
}

Merrill Singer

\begin{abstract}
Notable among gaps in the achievement of the global health Millennium Development Goals (MDG) are shortcomings in addressing maternal health, an issue addressed in the fifth MDG. This shortfall is particularly acute in Sub-Saharan Africa (SSA), where over half of all maternal deaths occur each year. While there is not as yet a comprehensive understanding of the biological and social causes of maternal death in SSA, it is evident that poverty, gendered economic marginalization, social disruptions, hindered access to care, unevenness in the quality of care, illegal and clandestine abortions, and infections are all critical factors. Beyond these factors, this paper presents a review of the existing literature on maternal health in SSA to argue that syndemics constitute a significant additional source of maternal morbidity and mortality in the region. Increasing focus on the nature, prevention, and treatment of syndemics, as a result, should be part and parcel of improving maternal health in SSA.
\end{abstract}

Keywords: Syndemics, Coinfection, Maternal health, Sub-Saharan Africa, Millennium development goals

\section{Multilingual abstracts}

Please see Additional file 1 for translations of the abstract into the six official working languages of the United Nations.

\section{Review}

Quandaries in health development and pregnancy in Sub-Saharan Africa

As 2015 draws near, Gorman [1] highlights the fact that although there has been notable progress in several critical areas of global health, one of the Millennium Development Goals (MDGs) adopted at the 2000 Millennium Summit "has been particularly recalcitrant to progress... namely, improving maternal health." The risk of a woman dying as a result of pregnancy or childbirth is about one in six in the poorest nations of the world compared with about one in 30,000 in the wealthy nations of Northern Europe [2]. The United Nations Secretariat [3] estimated that almost 300,000 maternal deaths occurred in 2010, $56 \%$ of them in Sub-Saharan Africa (SSA). With a maternal mortality rate of 640 maternal deaths per 100,000 live births [4], achieving MDG-5 in SSA is proving to be a formidable challenge. More broadly, maternal survival has

Correspondence: Merrill.Singer@Uconn.edu

Department of Anthropology and Department of Community Medicine, University of Connecticut, Storrs, CT 06269, USA been a comparatively neglected area in global health [5,6], suggestive of the longstanding primacy of focusing on fetuses and children, and not mothers, in maternal and child health programming [7]. Reflective of this shortcoming, as Gorman affirms, there is not as yet a full understanding of the biological and social causes of maternal death in SSA, although it is clear that poverty, gendered economic marginalization, social disruptions, access to care, quality of care, illegal and clandestine abortions, and infections are all critical factors [8-10]. The question has been raised: is achieving MDG-5 an impossible dream [11]?

Pregnancy is a unique immune condition that often has been characterized as a highly risky state for the mother and fetus alike. As Mor and Cardenas [12] note, for example, "Pregnant women in malaria-endemic regions are more susceptible to malaria infection during the first half of the pregnancy and this risk gradually declines during the second half. Lassa fever, caused by infection with an arenavirus showed a higher rate of case fatality in pregnant women particularly in the third trimester". Additionally, pregnancy may increase susceptibility and increase rates of mortality due to various infection diseases [13].

Compared to other world regions, infection as a cause of maternal death is especially prominent in SSA [14]. While it is evident that vulnerability to infection during 
pregnancy is conditioned by various factors, including the stage of the pregnancy, the nature of the disease challenge, the health of the mother prior to becoming pregnant, and access to quality health care, most existing discussions consider the immune challenge mounted by a single infectious agent. But what of the ability of the immune systems of pregnant women to respond to comorbid disease challenges, including diseases that are known to interact adversely in dually or multiply infected individuals? Moreover, what of the role of reciprocal actions during pregnancy involving the deleterious interface of infectious and noninfectious conditions? Adverse disease interactions, or syndemics, have been shown in recent years to play a significant detrimental role in the health of vulnerable populations [15].

The purpose of this paper is to emphasize the potential degree of influence of syndemics based on a review of an uneven, in many ways limited, but nonetheless suggestive, literature on the health of pregnant women in SSA. Focusing specifically on women's health, I argue that among the issues that must be addressed to a greater extent in health development efforts in the region are the emergence of an increased and more systematic awareness of, and response to, the syndemics of pregnancy.

\section{The biosocial model of syndemics}

The predominant biomedical and epidemiological models of disease stress isolated focus on individual threats to health. Such models rest on three underlying assumptions: every case of illness has a single underlying cause, a specific and identifiable disease is the source of each illness, and removal or reduction of the disease will produce a return to health [16]. Yet, as Valderas et al. [17] stress, on a daily basis biomedical practitioners treat "individuals with multiple coexisting diseases, who are now the norm rather the exception". That the great majority of patients, as well as sufferers not in care, have more than one health problem at any given moment needs to be explicitly acknowledged if the health impacts of disease complexity are to be effectively addressed.

Feinstein [18] introduced the concept of comorbidity to label the co-occurrence of diseases or other disorders. It has become increasingly apparent how important this concept is in health. A study of comorbidity in Canada, for example, concluded that findings on the high prevalence of multiple conditions "call into question the very organization of our health services [19]." In SSA, it is likely that the significance of comorbidity for population health and individual patient treatment is several magnitudes greater than in Canada, creating what Levitt et al. [20] term a health "collision course": "Noncommunicable diseases ... are emerging, and their risk factors are becoming more common as lifestyles change and rates of urbanization increase. Simultaneously, epidemics of infectious diseases persist, and HIV/AIDS has taken hold in the region". Indeed, it has been suggested that SSA is in the midst of a profound health transition involving a quadruple burden of infectious, noninfectious, injuryrelated, and perinatal and maternal health problems [21]. As a result, Starfield [22], who believes focus should not be on individual threads but on the "tapestry of morbidity," suggests that patients "should be characterized by their morbidity burden and, more importantly, by the patterns of morbidity that they experience with time".

With an understanding of the force of comorbidity in health, a syndemics orientation draws attention to two critical issues. First, diseases can transition beyond copresence to consequential adverse interaction. Second, the clustering of diseases in populations and the enhanced vulnerability of particular groups is often a result of social conditions and the unequal structure of social relationships. The differences between the terms comorbid and syndemic, as Mustanski et al. stress [23], is not simply semantic. Research guided by a comorbidity model tends to focus on the disease boundaries, overlaps, and prioritization, while syndemic research directs attention to "communities experiencing co-occurring epidemics that additively increase negative health consequences [23]". The adverse synergistic interaction of diseases in syndemics, in other words, multiplies the burden of disease in a population, and, under given conditions, can escalate contagion, disease progression, disability, and mortality. Stall et al. [24] introduced the syndemic production model, which posits that the greater the number of conditions in a syndemic interaction, the more adverse the health outcomes.

Vulnerability to syndemics involves both factors that put groups in harm's way for clusters of disease, as well as factors that contribute to the weakening of bodies, the degrading of immune capacities, the failing of social support systems, and the disruption or inaccessibility of healthcare services. Commonly, these are social conditions, such as structural inequalities, which produce chronic stress, inadequate diets, exposure to physical and emotional traumas, gender or other discrimination, and involvement in risky behaviors such as survival or coping mechanisms [15,25]. These kinds of social encumbrances "get under the skin" and have direct impact not only on disease development and progression, but on deleterious disease interaction as well.

Syndemics, in short, involve both biological and social factors and their pathways of interaction, mechanisms of disease promotion, and enhanced health impacts. Syndemic theory draws attention to, and provides a framework for, the analysis of these biosocial interactions, including their causes and consequences for human life and 
well-being [26-28]. Syndemics research has examined the entwined biological and social vulnerabilities and health profiles of various populations [24,29-35]. The biosocial contingencies of pregnancy generally and how these are enhanced in particular settings in SSA constitute a pressing domain of syndemics investigation.

The syndemics of pregnancy in SSA can be categorized for the purposes of analysis into three types: infectious syndemics, mixed infectious/noninfectious syndemics, and noninfectious syndemics. Each of these will be reviewed in turn based on the available literature.

\section{Infectious syndemics of pregnancy in Africa}

Infectious diseases still cause the majority (69\%) of deaths in SSA [36]. Several diseases are of particular note, including HIV, malaria, and tuberculosis (TB).

\section{Syndemics of HIV disease}

Meta-analysis of available global research on the contribution of HIV disease to maternal mortality has identified a pooled attributable risk across studies of 994 per 100,000 women [37]. Of the world's regions, the contribution of HIV disease to maternal mortality is highest in SSA, accounting for an estimated 207,000 (9\%) of deaths between 1990 and 2008 among pregnant and immediate postpartum women [4]. Other estimates suggest pregnancy-related HIV deaths as high as $25 \%$ of all maternal deaths for the region [37]. A secondary analysis of pooled community-based data for Sub-Saharan countries by Zaba et al. [38] found that excess mortality attributable to HIV was 51.8 (ranging across data sets from 47.8-53.8) per 1,000 person-years in women who were not pregnant or postpartum, and $11.8(8.4-15.3)$ per 1,000 person-years in pregnant or postpartum women. These researchers also found that HIV-infected pregnant or postpartum women have a mortality rate that is eight times higher than their HIV-uninfected counterparts. Sub-Saharan countries experiencing increases in maternal deaths in the midst of the campaign to achieve MDG-5, such as Botswana, Swaziland, Lesotho, and South Africa, are all in the subregion of the continent with the highest prevalence of HIV disease. This recognized significant impact of HIV disease on maternal health notwithstanding, there is recognition that "remarkably little is known about the mortality attributable to HIV during the pregnancy and postpartum period [37]". One area in need of greater understanding is the role of HIV-related disease interactions in maternal illnesses (e.g., anemia, postpartum hemorrhage and puerperal sepsis) and death.

What is known is that HIV disease is highly syndemogenic [15]. A key reason it has become one of the major diseases of human history is its considerable capacity to participate in damaging disease interactions of three types. First, interactions with opportunistic diseases that generally are only able to take hold because of immunodeficiency resulting from HIV disease. Second, interactions with a set of commonly non-opportunistic diseases, such as TB, hepatitis, malaria, and various STDs. Finally, HIV disease interacts adversely with various noninfectious diseases and disorders, including food insufficiency/malnourishment, among others. Each of these will be discussed in turn.

\section{HIV interaction with opportunistic diseases}

There are multiple opportunistic diseases found among HIV-infected pregnant women [39,40]. A study of this population at a large HIV treatment center in Lagos, Nigeria found that the most prevalent opportunistic diseases were oropharyngeal and vaginal candidiasis (24.0\% of identified opportunistic disease cases), bacterial infections including pneumonia (12.9\%), Herpes zoster (5.3\%), and diarrheal diseases (18.1\%) [41]. These opportunistic diseases were found to be an important predictor of anemia, a well-recognized risk for heightened morbidity and mortality in pregnant women $[42,43]$. Analysis of data from the Saving Mothers Report, 2005-2007 by Moran and Moodley [44] found that the most common cause of maternal deaths in known HIV-infected women in South Africa (accounting for $43.7 \%$ of all maternal deaths) were nonpregnancy-specific opportunistic diseases such as meningitis and pneumonia. Opportunistic diseases, including meningitis, toxoplasmosis, encephalitis, and pneumonia, were found by Onakewhor and coworkers [45] to be important factors in maternal mortality in Benin City, Nigeria.

An examination was conducted by Djigma et al. [46] on the prevalence of bacterial vaginosis-the most common vaginal infection in women of childbearing age-in 251 HIV-positive compared to $200 \mathrm{HIV}$-negative women at a maternal and child health program in Burkina Faso. They found a range of vaginal pathogens, including several associated with sterility. Nugent's scores, a Gram-stain scoring system used to diagnose bacterial vaginosis, were significantly higher in HIV-positive women ( $\mathrm{p}<0.001)$. As these studies suggest, various opportunistic diseases remain important factors shaping maternal health among HIV-infected women in SSA.

\section{HIV interaction with non-opportunistic diseases}

One of the significant non-opportunistic diseases with which HIV disease increasingly interacts in SSA is TB [47]. While sometimes described as an opportunistic disease, TB has a protracted history as a serious human ailment that long predates the emergence of HIV disease [48]. According to the World Health Organization, maternal TB, which may be harder to detect because of the masking effects of pregnancy, causes a two-fold increase in vaginal bleeding, eclampsia, and pre-eclampsia [49]. Recent research has identified the development of active 
TB in HIV-infected women in parts of SSA as a grave risk factor for maternal health [50-52]. Because of several pathways of interaction, including HIV reactivation of latent TB and bidirectional disease enhancement involving accelerated progression of both HIV disease and TB, in combination, these two diseases have been shown to have significantly greater impact than the mere addition of their individual effects. This pattern was described by Pillay et al. [53] based on a review of existing studies showing that approximately one-sixth of all maternal deaths in referral health centers in southern Africa were associated with TB/HIV coinfection. Further, over one-third (37\%) of HIV-infected mothers who were dually infected with TB were severely immunocompromised, with $\mathrm{CD} 4$ counts of fewer than 200 cells/microL compared with $14-19 \%$ in mothers enrolled in mother-to-child intervention trials in Europe.

Exemplary of TB/HIV coinfection research, Khan et al. [54] examined maternal mortality at King Edward III Hospital in Durban, South Africa, located in an area where TB and HIV have emerged as significant entwined contributors to maternal mortality. They found a mortality rate of 323/100,000 among HIV-infected women, compared to $148.6 / 100,000$ among uninfected women. Ninety-three percent (14 of 15) of mothers diagnosed with TB were coinfected with HIV. The hospital-based mortality rate for TB and HIV coinfection was 121.7/ 1,000; for TB without HIV coinfection, this rate was $38.5 / 1,000$ or about one third the rate of HIV-infected women. Generally, in late HIV disease, women are more likely to have clinical TB, so active TB may be a marker of late HIV disease, as well as an increased risk of death as a result of the comorbidity. Still unresolved in the literature is the issue of pregnancy effects (e.g., added biological and metabolic costs) of TB/HIV interaction, progression, and adverse outcomes.

Another HIV syndemic threat to maternal health involves coinfection with malaria. At early stages in pregnancy, a transient depression of cell-mediated immunity occurs that increases susceptibility to malaria, especially in primagravid and secundigravid women [55]. Independent of HIV, maternal malaria is associated with anemia and maternal mortality [56-58]. It is estimated that $15 \%$ of maternal anemia in SSA is linked to malaria and a range of other adverse outcomes [59,60]. It is further estimated that one million pregnancies per year in the region are adversely complicated by coinfection of malaria and HIV disease [61].

Maternal HIV disease is associated with an increased risk of maternal malaria in women of all gravidities in endemic areas, but perhaps not equally so [62]. In a study of women who presented at two rural hospitals in southern Malawi for antenatal care and for delivery, prevalence of HIV disease was $25.6 \%$ [63]. In this sample, among women who were pregnant for the first time, prevalence for malaria at enrollment was $56.3 \%$ in HIV-infected, and $36.5 \%$ in HIV-uninfected, women. For multigravid women, the corresponding rates were $23.8 \%$ and $11.0 \%$, respectively. HIV-infected primagravid women exhibited increased malaria prevalence at all gestational stages. The relative risk for malaria infection in HIV-infected women compared to HIV-uninfected women was significantly increased in most parity groups, including women with more than three prior pregnancies (95\% CI: 0.31-5.29), suggesting that parity-specific immunity to malaria (found in HIV-negative women) was impaired in dually infected women. Malaria prevalence at delivery remained high in HIV-infected women even among those pharmaceutically treated for infection.

The importance of HIV in malaria infection is further indicated by a study in Kinshasa, Democratic Republic of Congo. In the study, Modia et al. [64] compared 146 HIV-infected and 149 HIV-uninfected mothers. Placental biopsies confirmed the presence or absence of placental malaria. These researchers found that the placental malarial infection prevalence was $91 \%$ among HIV-infected mothers but only $53.7 \%$ in HIV-uninfected mothers ( $\mathrm{p}<$ 0.0001). Similarly, in a study of 986 pregnant women admitted during the rainy season to the obstetric division of a district hospital in northern Zimbabwe, researchers found that HIV-infected women were more likely to develop malaria attacks-defined as the presence of asexual forms of Plasmodium species on a blood smear associated with fear, headache, chills, and/or joint pain-during their pregnancies than women who were seronegative (odds ratio $=3.96,95 \%$ CI: 2.42-6.46) [65]. In a public hospital in western Kenya, HIV-seropositive women coinfected with malaria were twice as likely to suffer from anemia as HIV-seronegative women with or without malaria infection [66]. These findings are of note because under conditions of climate change and extensions in the ranges of malaria vectors, the location and frequency of syndemic interaction of HIV and malaria is likely to increase [67].

Adverse interactions with hepatitis infections, which share common modes of transmission with HIV, constitute another group of non-opportunistic HIV syndemics among pregnant women in SSA. Hepatitis $C$ infection $(\mathrm{HCV})$ is disproportionately common in Africa, which is reported to have the highest prevalence rate (prevalence $=$ $5.3 \%$ ) of the world's regions, while the largest reservoirs of chronic hepatitis B (HBV) infection are in SSA (prevalence $=\geq 8 \%$ ) and Asia (prevalence $=>8 \%$ ) $[68,69]$. HIV is known to adversely impact the course of both HBV and $\mathrm{HCV}$ infections by accelerating the progression of chronic liver disease. Among individuals previously exposed to $\mathrm{HBV}$ in which disease development was contained by the immune system, for example, severe immunosuppression caused by HIV can lead to HBV reactivation [68]. Both 
types of hepatitis have been identified as risk factors among pregnant women, and are believed to be leading causes of maternal mortality in some SSA nations [70,71]. In a study of HIV/HCV coinfection among 547 pregnant women attending the antenatal clinic of a medical center in Ouagadougou, Burkina Faso, Simpore et al. [72] found that $10.6 \%$ were positive for HIV disease and $3.3 \%$ for $\mathrm{HCV}$ disease. Seven women in the sample $(1.3 \%)$ were dually infected (compared to 76 women with a single infection), a higher than expected rate "suggesting a correlation between these two infections [72]". A follow-up study of 607 women found higher rates of HCV in HIVpositive women than their HIV-negative counterparts ( $2.38 \%$ versus $1.75 \%$, respectively), but not at statistically significant levels $(P=0.81)$ [73]. Similarly, a study of pregnant women in Zambia found somewhat higher levels of HBV infection among HIV-positive pregnant women [74].

In a study of over 1,000 pregnant women (half HIVpositive) in Abidjan, Côte d'Ivoire, researchers tested for $\mathrm{HBV}$ and HCV infection [75]. They found that HBV was more frequent in HIV-positive women (26.7\%), compared to HIV-negative women (9.4\%). By contrast, there were no differences in the rates of $\mathrm{HCV}$ infection in the two HIV-status groups. A study in Ibadan, Nigeria also found greater coinfection with $\mathrm{HBV}(8.9 \%)$ than $\mathrm{HCV}$ (1.9\%) in HIV-infected pregnant women [76].

In another study that examined both $\mathrm{HBV}$ and $\mathrm{HCV}$ among HIV-positive pregnant women in the region, Okeke and co-workers [77] implemented a retrospective survey of approximately $400 \mathrm{HIV}$-positive pregnant women in Enugu, Nigeria. The combined prevalence of HIV/HBV and $\mathrm{HIV} / \mathrm{HCV}$ coinfection was $6.5 \%$, with HIV/HBV coinfection being the more common dual infection pattern. Of note, a study of six viral infections among pregnant women $(\mathrm{N}=492)$ and blood donors $(\mathrm{N}=191)$ in rural and urban (Ouagadougou) Burkina Faso found that $0.6 \%$ of participants were triply infected, with the most common coinfection array involving $\mathrm{HBV}, \mathrm{HIV}$, and human herpesvirus type 8 (HHV-8) [78]. The same trichotomous syndemic was examined in a second Burkina Faso study among over 375 women seeking antenatal consultation at Saint Camille Medical Centre in Ouagadougou [79]. Among HBVpositive patients, HIV and HHV-8 coinfections were high, comprising $16.7 \%$ and $20 \%$, respectively, of women who tested positive for hepatitis exposure. Additionally, of the $12.7 \%$ of women who were positive for HIV-1, $4.2 \%$ also were coinfected with HIV-2. At the same medical center, Ouermi and colleagues (2009) [80] investigated coinfections of HBV and Toxoplasma gondii-a parasitic protozoan that causes toxoplasmosis-in HIV-positive and HIV-negative pregnant women. They found that HIVpositive status was associated with higher prevalence rates of both T. gondii (31.9 vs. 22.5\%, 95\% CI: 24.36-40.43) and HBV (13.0 vs. $5.8 \%, 95 \%$ CI: 8.12-20.09).
As these studies suggest, the extent of the HIV disease/ hepatitis syndemic, along with other coinfections, among pregnant women in SSA is currently low but higher for $\mathrm{HBV} / \mathrm{HIV}$ than HCV/HIV coinfection. Changes in risk patterns, such as the growing spread of injection drug use and risky sexual practices among youth and young adults, however, could alter this profile and produce impactful syndemics involving HIV and hepatitis [81,82].

\section{HIV interaction with noninfectious diseases and disorders}

The third group of diseases and health conditions that HIV disease interacts with includes various noninfectious diseases and disorders, such as food insufficiency [83-85]. These terms are defined as persistent lack of access to adequate food in needed quantity and quality (food insecurity), and deficiencies in micronutrients and macronutrients (undernutrition) [86]. A mother's nutritional status is a critical determinant of maternal health [87]. In SSA, HIV disease has spread rapidly among populations in which malnutrition is endemic. Syndemic interaction between these two health threats is centered in the body's complex and multilayered host immune system [88]. In fact, malnutrition and HIV disease are the two most common causes of acquired immune dysfunction, and the patterning of immune system suppression caused by malnutrition mirrors, in many ways, the downgraded immune effects of HIV disease. The pathways of interaction are bidirectional. While HIV disease exacerbates nutrient deficiencies by altering critical metabolic processes involved in nutrient intake and utilization, chronic undernutrition weakens the body's immune response, leading to reductions in immune cell populations and immunocompetence. These dynamics have been identified as a significant threat to pregnant women in SSA [89-92].

Beyond HIV disease, a range of other infectious syndemics impacts the health of pregnant women in SSA. One of these noteworthy in the region is the interaction of malaria and helminth infections.

\section{Malaria and helminths}

The conditions for a potential syndemic of these two parasitic infections are created by the overlapping geographic distributions of mosquito vectors of malaria and the various species of intestinal helminths. An assessment of over 1,000 febrile patients in southern Ethiopia found that malaria infection was more common in patients coinfected with the helminths A. lumbricoides (21.3\%), T. trichiura (23.1\%), and S. mansoni (23.1\%) than those patients without a helminth infection (9.3\%) [93]. The prevalence of non-severe malaria was significantly higher in individuals infected with specific helminths (A. lumbricoides-35.9\%, T. trichiura-11.7\%, S. mansoni-9.8\%, and hookworm-9.8\%, respectively) than 
those who were not so infected (9.3\%) (adjusted OR $=1.58$, 95\% CI: 1.13-2.22). Moreover, the odds ratio of having non-severe malaria increased with the number of intestinal helminth species infecting a patient $(\mathrm{p}<0.001)$. Coinfected individuals showed lower mean levels of hemoglobin than those with malaria infection alone $(\mathrm{p}=0.027)$. The specific helminth species involved may be critical, as some findings suggest a protective or counter-syndemic effect with particular types of intestinal worms and a worsening syndemic effect with others [94]. Hookworm, for example, falls into the latter group, which is consequential both because its prevalence in SSA among pregnant women is high and because it "may contribute significantly to the degree of anemia in pregnant women [95]".

Several hypotheses have been put forward to explain the nature of the interaction between helminths and malaria. A review by Mwangi et al. [96] highlights the possibility that helminth infection creates a cytokine milieu that is favorable to the production of noncytophilic antibodies, making individuals more susceptible to clinical malaria. Alternately, Yazdanbakhsh et al. [97] suggest that the presence of T-regulatory cells increase during helminth infection, which, if present in sufficient numbers, induce a non-specific immune suppression that facilitates malaria development upon exposure. As yet, given the limited availability of studies, the relative value of these hypotheses remains uncertain [98].

First described over 75 years ago, it is clear that dual infection of malaria and intestinal helminths presents a serious threat to the health of pregnant women in SSA [99]. Varying patterns of coinfection have been described. A cross-sectional study of women presenting for delivery at two hospitals in Kumasi, Ghana, found that $19.7 \%$ were positive for the malarial pathogen $P$. falciparum, 9.1\% were positive for helminth infection without malaria, and $16.6 \%$ were coinfected [100]. Several helminths were identified, including hookworms, A. lumbricoides, T. trichiura, and $S$. stercoralis, with the first two being the most common. Women with intestinal helminths were almost five times as likely to be infected with malaria as women without a helminth infection. Young age at pregnancy was found to be strongly associated with dual infection, while heightened rates of dual infection also were found among single, low-income, and primagravid women. Hiller et al. [101] observed "a strong association between asymptomatic infection with $P$. falciparum and infection with [the helminth] $M$. perstans" in a randomized, doubleblind, placebo-controlled treatment study among pregnant women in Entebbe, Uganda. A weaker association was observed between hookworm and P. falciparum infection. Egwunyenga et al. [95] randomly selected over 2,000 nearterm pregnant women who delivered at three hospitals in Nigeria for screening for malaria and helminth parasites. Their study revealed that over $45 \%$ of Plasmodium infected women also harbored intestinal helminths. Women, especially primagravids, with Plasmodium/ intestinal helminth coinfections had lower hemoglobin levels than those who suffered from malaria infection alone. This condition was attributed to chronic loss of blood and iron due to both infections. Anemia was believed to be further aggravated by the poor nutritional status of study participants, especially involving limited access to folate and iron.

Taking the assessment of disease interaction another step, Crowther et al. [102] examined the interplay of malaria, helminths, and HIV disease among 328 HIV-positive women attending antenatal centers in Rwanda. They found that $38 \%$ tested positive for helminths, $21 \%$ had malaria, and $10 \%$ had dual infection. The most prevalent helminth was A. lumbricoides (20.7\%), followed by $T$. trichiura (9.2\%). Women with helminth infections were characterized by low hemoglobin and CD4 counts $(\mathrm{p}<0.05)$. This study demonstrates the importance of assessing multidisease syndemics among pregnant women. In low-income settings in particular, pregnant women may be subject to complex syndemics involving more than two diseases in adverse interaction.

\section{Mixed infectious/noninfectious syndemics}

Syndemics, as indicated, are not limited to pathogenpathogen interactions involving infectious diseases, but also include adverse interplay of infectious and noninfectious diseases. It has been established that some infections increase the risk of certain noninfectious diseases and vice versa. Among pregnant women in SSA, this is seen in the TB/diabetes syndemic. Diabetes considerably increases risk of early mortality due to TB [103]. This association may be produced both through the role of diabetes in impairing immune functions and through its interference with the effectiveness of pharmaceutical treatment of TB [104]. Bidirectional impact, involving TB increasing the risk of diabetes, also has been described [15]. Dietary deficiencies, including inadequacies of vitamins $\mathrm{A}, \mathrm{C}$, and $\mathrm{D}$, have been linked to increased risk for both diabetes and TB [104]. In SSA, diabetes has been associated with a three-fold incident risk of TB and increased prevalence of diabetes has been identified in patients with pulmonary TB [105-107]. The precise impact of the convergence of these two diseases among pregnant women in SSA, which is expected given the rising prevalence of diabetes and the existing prevalence of $\mathrm{TB}$, remains uncertain because as Dooley and Chaisson [108] found in review of the relevant literature: "Many important topics have been poorly studied or not studied at all".

\section{Noninfectious syndemics}

Noninfectious syndemics, involving interaction among chronic diseases and health conditions, are also of 
critical importance. In the case of pregnant women in SSA, this is seen in the interaction of diabetes and undernutrition. Diabetes contributes to anemia during pregnancy and maternal morbidity [109,110]. Prevalence rates of gestational Type 2 diabetes are increasing globally including in SSA [111]. Gestational diabetes (GDM) is associated with an increased risk for the subsequent development of classical diabetes mellitus. While studies of GDM are limited in African countries [110], one of the highest rates (3.7\%) has been found among rural pregnant women in northern Ethiopia [112]. In accounting for this level of prevalence, the authors suggest the importance of nutritional deficiency: "The only possible reason found to be a cause for the high prevalence of GDM in this area is the exposure of these pregnant women to chronic malnutrition during their intrauterine life and early child hood periods. Drought, famine and war have persistently affected this area where the study was conducted for the last over 50 years [112]". In other research, marginal food security has been found to be significantly associated with GDM [113].

\section{Conclusion}

Pregnant women, particularly in SSA, are an understudied group, but they are more vulnerable to infections because of suppression of the immune system during pregnancy and also are at heightened risk for various noninfectious diseases as well. While amplified vulnerability is recognized, epidemiological, biomedical, and social science of health research about pregnant women has tended to be characterized by "single disease" approaches. In this paper, I have reviewed available literature suggesting the critical importance of adverse disease interactions of infectious and noninfectious diseases to draw attention to the role of syndemics in maternal health in the region.

The strength of the findings of this review are limited by several factors, including the size and significant diversity of the countries and locales of SSA, the burdens of research common to resource-poor settings, the comparatively few studies focused specifically on maternal health in the region, the dominance of narrowly-focused prevalence studies, the small number of ethnographic assessments that present the experience and perspective of pregnant women on their health, and the restricted attention paid to comorbidity, let alone to the nature, pathways and consequences, of disease interaction. Nonetheless, the available literature is adequate to suggest the salience of the syndemics of pregnancy in the countries under examination. Capacity-strengthening efforts designed to improve the number and quality of syndemic "burden-ofdisease" studies could provide critical knowledge for the implementation of programs capable of improving the quality of care and maternal health in SSA. Such studies would explore the constellation of diseases of pregnant patients; would investigate locally-identified syndemics and their health effects during pregnancy including the patterns of presentation of specific interacting diseases, the social conditions that foster disease clustering and interaction among pregnant women; and involve trials of integrated treatment regimens designed to treat multiple co-occurring diseases in this population.

Ray and co-authors [114] argue that "failure to reduce preventable maternal deaths represents a violation of women's right to life, health, non-discrimination and equality." They advocate an activist approach, involving collaboration of health professionals and non-government civil organizations for improving material health in the African context. As a model for such an initiative, they point to grassroots HIV activism and its successful rightsbased challenge. Thus, they note: "With regard to maternal mortality, where the majority of deaths are preventable and in many countries occur in health institutions, there are opportunities to learn from the successes of HIV campaigns in making health services more responsible to women's needs [114]". As an example of this kind of activism in women's health, they point to the Treatment Action Campaign in South Africa, which used a right to health approach, community empowerment, popular mobilization, and legal action. The syndemics model, which emphasizes the social origins of disease and the need for health care response to the entwined biosocial complexities of living conditions, gender discrimination, pregnancy under conditions of poverty, and the role of a constellation of interacting diseases can inform activist efforts to improve maternal health in SSA.

\section{Additional file}

Additional file 1: Multilingual abstracts in the six official working

languages of the United Nations.

\section{Abbreviations}

GDM: Gestational diabetes; HBV: Hepatitis B virus; HCV: Hepatitis C virus; HIV: Human immunodeficiency virus; MDGs: Millennium development goals; SSA: Sub-Saharan Africa; TB: Tuberculosis.

\section{Competing interests}

The author declares that he has no competing interests.

\section{Acknowledgement \\ The author thanks Balya Ostrach for her suggested revisions based on an earlier draft of this paper.}

Received: 18 July 2013 Accepted: 4 November 2013

Published: 15 November 2013

\section{References}

1. Gorman S: A new approach to maternal mortality: the role of HIV in pregnancy. Int J Women's Health 2013, 5:271-274.

2. Ronsmans C, Graham W: Maternal mortality: who, when, where, and why. Lancet 2006, 368(9542):1189-1200. 
3. United Nations Secretariat: The Millennium Development Goals Report. New York United Nations; 2012. Available from: http:/www.undp.org/content/dam/undp/ library/MDG/english/The_MDG_Report_2012.pdf. Accessed June 20, 1013.

4. World Health Organization: Trends in Maternal Mortality: 1990 to 2008. Geneva: WHO; 2010. Available from: http://whqlibdoc.who.int/publications/ 2010/9789241500265 eng.pdf. Accessed June 23, 2013.

5. AbouZahr C: Global burden of maternal death and disability. Br Med Bull 2003, 67(1):1-11.

6. Horton R: Healthy motherhood: an urgent call to action. Lancet 2006, 368(9542):1129.

7. Rosenfield A, Maine D: Maternal mortality: a neglected tragedy: where is the $\mathrm{M}$ in $\mathrm{MCH}$ ? Lancet 1985, 326:83-85.

8. Harrison K: Maternal Mortality in Nigeria: the real issues. Afr J Reprod Health 1997, 1(1):7-13.

9. Jambai A, MacCormack C: Maternal health, war, and religious tradition: authoritative knowledge in Pujehun District, Sierra Leone. Med Anthropol Q 1996, 10(2):270-286.

10. Spangler S: "To open oneself Is a poor woman's trouble": embodied inequality and childbirth in South-Central Tanzania. Med Anthropol Q 2011, 25(4):479-498.

11. Rosenfield A, Maine D, Freedman L: Meeting MDG-5: an impossible dream? Lancet 2006, 368(9542):1133-1134.

12. Mor G, Cardenas I: The immune system in pregnancy: a unique complexity. Am J Reprod Immunol 2010, 63(6):425-433.

13. Jamieson D, Theile R, Rasmussen S: Emerging infections and pregnancy. Emerg Infect Dis 2006, 12(11):1638-1643.

14. Khan K, Wojdyla D, Say L, Gulmezoglu A, Van Look P: WHO analysis of causes of maternal death: a systematic review. Lancet 2006, 367:1066-1074.

15. Singer M: Introduction to Syndemics. San Francisco: Jossey-Bass; 2009.

16. Wade $D$, Halligan P: Do biomedical models of illness make for good healthcare systems? BMJ 2004, 329(7479):1398-1401.

17. Valderas J, Starfield B, Sibbald B: Defining comorbidity: implications for understanding health and health services. Ann Fam Med 2009, 7(4):357-363.

18. Feinstein $A$ : The pre-therapeutic classification of co-morbidity in chronic disease. J Chronic Dis 1970, 23:455-468.

19. Fortin M, Bravo G, Hudon C, Vanasse A, Lapointe L: Prevalence of multimorbidity among adults seen in family practice. Ann Fam Med 2005, 3:223-228.

20. Levitt N, Steyn K, Dave J, Bradshaw D: Chronic noncommunicable diseases and HIV-AIDS on a collision course: relevance for health care delivery, particularly in low-resource settings-insights from South Africa. Am J Clin Nutr 2011, 94(6):1690-1696.

21. Mayosi B, Flisher A, Lalloo U, Sitas F, Tollman S, Bradshaw D: The burden of non-communicable diseases in South Africa. Lancet 2009, 374(9693):934-947.

22. Starfield B: Threads and Yarns: weaving the tapestry of comorbidity. Ann Fam Med 2006, 4(2):101-103.

23. Mustanski B, Garofalo R, Herrick A, Donenberg G: Psychosocial health problems increase risk for HIV among urban young men who have sex with men: preliminary evidence of a syndemic in need of attention. Ann Behav Med 2007, 34:37-45.

24. Stall R, Friedman M, Catania J: Interacting epidemics and gay men's health: a theory of syndemic production among urban gay men. In Unequal Opportunity: Health Disparities Affecting Gay and Bisexual Men in the United States. Edited by Wolitski R, Stall R, Valdiserri R. Oxford: Oxford University Press; 2007:251-274.

25. Berer M: Maternal mortality or women's health: time for action. Reprod Health Matters 2012, 20(39):5-10.

26. Himmelgreen D, Romero-Daza N, Turkon D, Watson S, Okello-Uma I, Sellen D: Addressing the HIV/AIDS-food insecurity syndemic in sub-Saharan Africa. Afr J AIDS Res 2009, 8(4):401-412.

27. Sattenspiel $L$, Herring $A$ : Emerging themes in anthropology and epidemiology: geographic spread, evolving pathogens and syndemics. In A Companion to Biological Anthropology. Edited by Spencer Larsent EC. Malden, MA: Wiley; 2010:167-178.

28. Singer M, Bulled N: Interlocked infections: the health burdens of syndemics of neglected tropical diseases. Ann Appl Anthropol 2013, 36(2):326-343.

29. González-Guarda R, Florom-Smith A, Thomas T: A syndemic model of substance abuse, intimate partner violence, HIV infection, and mental health among Hispanics. Public Health Nurs 2011, 28(4):366-378.
30. Halkitis P, Moeller R, Siconolf, Storholm E, Solomon T, Bub K: Measurement model exploring a syndemic in emerging adult gay and bisexual men. AIDS Behav 2012. Epub ahead of print.

31. Herring DA, Sattenspiel L: Social contexts, syndemics, and infectious disease in Northern Aboriginal populations. Am J Hum Biol 2007, 19:190-202.

32. Kelly $P$, Cheng A, Spencer-Carver E, Ramaswamy M: A syndemic model of women incarcerated in community jails. Public Health Nurs 2013. (in press). doi.org/10.1111/phn.12056

33. Kline N: "There's nowhere I can go to get help, and I have tooth pain right now": the oral health syndemic among migrant farmworkers in Florida. Annals of Anthropological Practice 2013, 36(2):385-399.

34. Everett $M$, Wieland J: Diabetes among Oaxaca's transnational population: an emerging syndemic. Annals of Anthropological Practice 2013, 36(2):293-309.

35. Ostrach B, Singer M: At special risk: biopolitical vulnerability and HIV syndemics among women. Health Sociol Rev 2012, 21(3):258-271.

36. Young F, Critchley J, Johnstone L, Unwin N: Globalization and the dual disease burden in sub-Saharan Africa. Diabetes Voice 2010, 55(1):30-32.

37. Calvert C, Ronsmans C: The contribution of HIV to pregnancy-related mortality: a systematic review and meta-analysis. AIDS 2013, 27(10):1631-1639.

38. Zaba B, Calvert C, Marston M, Isingo R, Nakiyingi-Miiro J, Lutalo T, Crampin A, Robertson L, Herbst K, Newell M, Todd J, Byass P, Boerma T, Ronsmans C: Effect of HIV infection on pregnancy-related mortality in sub-Saharan Africa: secondary analyses of pooled community-based data from the network for analysing longitudinal population-based HIV/AIDS data on Africa (ALPHA). Lancet 2013, 381(9879):1763-1771.

39. Mclntyre J: Mothers infected with HIV. Br Med Bull 2003, 67(1):127-135.

40. Awolude O, Adesina O, Oladokun A, Mutiu W, Adewole I: Asymptomatic bacteriuria among HIV positive pregnant women. Virulence 2010, 1(3):130-133.

41. Eechi O, Kalejaiye O, Gab-Okafor C, Oladele D, Oke B, Ekama N, Ujah I: The burden of anaemia and associated factors in HIV positive. Nigerian women. Arch Gynecol Obstet 2013, 287:293-244.

42. Aimakhu C, Olayemi O: Maternal haematocrit and pregnancy outcome in Nigerian women. West Afr J Med 2003, 22(1):18-21.

43. Belperio $P$, Rhew D: Prevalence and outcomes of anemia in individuals with human immunodeficiency virus: a systematic review of the literature. Am J Med 2004, 116:27S-43S.

44. Moran N, Moodley J: The effect of HIV infection on maternal health and mortality. Suppl Int J Gynecol Obstet 2012, 119(Supplement 1):S26-S29.

45. Onakewhor J, Olabuji B, Ande A, Ezeanocie M, Olokor O, Okonofua F: HIV-AIDS related maternal mortality in Benin City, Nigeria. Ghana Med J 2011, 45(2):54-59.

46. Djigma F, Ouedraogo C, Sagna T, Ouermi D, Sanogo K, Bisseye C, Kabre A, Pietra V, Simpore J, Nikiema J, Musumeci S: HIV-infected women of Burkina Faso: a "reservoir" of mycoplasma infection. J Infect Dev Ctries 2011, 5(3):176-181.

47. Mnyani C, Mclntyre J: Tuberculosis in pregnancy. BJOG 2010, 118(2):226-231.

48. Bates J, Stead W: The history of tuberculosis as a global epidemic. Med Clin N Am 1993, 77(6):1205-1217.

49. UN Integrated Regional Information Networks: Africa: maternal and paediatric tuberculosis still overlooked. Available on line at: http://allafrica. com/stories/201306200503.html. Accessed June 30, 2013.

50. Ahmed Y, Mwaba P, Chintu C, Grange J, Ustianowski A, Zumla: A study of maternal mortality at university teaching hospital, Lusaka, Zambia: the emergence of tuberculosis as a major non-obstetric cause of maternal death. Int J Tuberc Lung Dis 1999, 3:675-680.

51. Gilks C, Brindle R, Otieno L, Bhatt S, Newnham R, Simani P, Lule G, Okelo G, Watkins W, Waiyaki P: Extrapulmonary and disseminated tuberculosis in HIV-1-seropositive patients presenting to the acute medical services in Nairobi. AIDS 1990, 4:981-985.

52. Leroy $V$, Msellati $P$, Lepage $P$, Batungwanayo J, Hitimana D, Taelman $H$, Bogaerts J, Boineau F, Van de Perre P, Simonon A, Batungwanayo J, Msellati P, Hitimana D-G, Begaerts J, Boineau F: Four years of natural history of HIV-1 infection in African women: a prospective cohort study in Kigal (Rwanda), 1988-1993. J Acquir Immune Defic Syndr Hum Retrovirol 1995, 9:415-421.

53. Pillary $\mathrm{T}$, Khan M, Moodley J, Adhikari M, Coovadia H: Perinatal tuberculosis and HIV-1: considerations for resource-limited settings. The Lancet, Infect Diseases 2004, 4(3):155-165.

54. Khan M, Pillay T, Moodley J, Connolly C: Maternal mortality associated with Tuberculosis-HIV coinfection in Durban, South Africa. Ann N Y Acad Sci 2000, 918:367-369. 
55. Riley E, Schneider G, Sambou I, Greenwood B: Suppression of cell-mediated immune responses to malaria antigens in pregnant Gambian women. Am J Trop Med Hyg 1999, 40:141-144.

56. Ching C, Songane F, Bergström S, Povey G: Coma in Mozambican gravidas: causes and perinatal outcome. J Trop Pediatr 1992, 38:100-102.

57. Hammerich A, Campbell O, Chandramohan D: Unstable malaria transmission and maternal mortality - experiences from Rwanda. Trop Med Int Health 2002, 7:573-76.

58. Steketee R, Nahlen B, Parise M, Menendez C: The burden of malaria in pregnancy in malaria-endemic areas. Am J Trop Med Hyg 2001, 64(suppl):28-35

59. Fievet N, Cot M, Chougnet C, Maubert B, Bickii J, Dubois B, Hesran J, Frobert $Y$, Migot F, Romain F, Verhave J, Louis F, Deloron P: Malaria and pregnancy in Cameroonian primigravidae, humoral and cellular immune responses to Plasmodium falciparum blood-stage antigens. Am J Trop Med Hyg 1995, 53:612-617.

60. Bouyou-Akotet M, lonete-Collard D, Mabika-Manfoumbi M, Matsiegu P Mavoungou E, Kombila M: Prevalence of plasmodium falciparum infection in pregnant women in Gabon. Malar J 2003, 2:18.

61. World Health Organization: Malaria and HIV/AIDS interactions and implications: conclusions of a technical consultation convened by WHO, 23-25. June 2004. Online at: http://www.who.int/malaria/malaria_HIV/malaria_hiv_flyer.pdf Accessed June 19, 2013

62. Van Eijk A, Ayisi J, Ter Kuile F, Feiko O, Misore A, Otieno J, Rosen D, Kager P, Steketee R, Nahlen Bernard L: HIV increases the risk of malaria in women of all gravidities in Kisumu, Kenya. AIDS 2003, 17:595-603.

63. Verhoeff F, Brabin BC, Anthony Hart C, Chimsuku L, Kazembe P, Broadhead $P$ : Increased prevalence of malaria in HIV-infected pregnant women and its implications for malaria control. Trop Med Int Health 1999, 4(1):5-12.

64. Modia O, Foidart J, Rigo J: Influence of HIV-1 and placental malaria coinfection on newborn biometry and Apgar scores in Kinshasa, democratic republic of Congo. Journal de Gynécologie Obstétrique et Biologie Reproduction 2011, 40(5):460-464.

65. Ticconi C, Mapfumo M, Dorrucci M, Naha N, Tarira E, Pietropolli A, Rezza G. Effect of maternal HIV and malaria infection on pregnancy and perinatal outcome in Zimbabwe. J Acquir Immune Defic Syndr 2003, 34(3):289-294.

66. Ayisi J, van Eijk A, ter Kuile F, Kolczak M, Otieno J, Misore A, Kager P, Steketee $R$, Nahlen B: The effect of dual infection with HIV and malaria on pregnancy outcome in western Kenya. AIDS 2003, 17(4):585-594.

67. Baer H, Singer M: Global Warming and the Political Ecology of Health: Emerging Crises and Systemic Solutions. Walnut Creek, CA: Left Coast Press; 2009.

68. Madhava V, Burgess C, Drucker E: Epidemiology of chronic hepatitis C virus infection in sub-Saharan Africa. Lancet Infect Dis 2002, 2:293-302.

69. Modi A, Feld J: Viral hepatitis and HIV in Africa. AIDS Rev 2007, 9:25-39.

70. Dafallah S, EL-Agib F, Bushra G: Maternal mortality in a teaching hospital in Sudan. Saudi Med J 2003, 24:369-373.

71. Elsheikh R, Daak A, Elsheisk M, Karsany M, Adam I: Hepatitis B virus and hepatitis C virus in pregnant Sudanese women. Virol J 2007, 4:104

72. Simpore J, Ilboudo D, Samandoulougou A, Guardo P, Castronovo P, Musumeci S: HCV and HIV coinfection in pregnant women attending St. Camille Medical Centre in Ouagadougou (Burkina Faso). J Med Virol 2005, 75(2):209-212.

73. Zeba M, Karou S, Sagna T, Djigma F, Bisseye C, Ouermi D, Pietra V, Pignatelli S, Gnoula C, Sia J, Moret R, Nikiema J, Simpore J: HCV prevalence and coinfection with HIV among pregnant women in Saint Camille Medical Centre, Ouagadougou. Trop Med Int Health 2011, 16(11):1392-1396.

74. Oshitani H, Kasolo F, Mpabalwani M, Mizuta K, Luo N, Suzuki H, Numazaki Y: Prevalence of hepatitis $B$ antigens in HIV-1 seropositive and seronegative pregnant women in Zambia. Trans R Soc Trop Med Hyg 1996 90:235-236.

75. Rouet F, Chaix M, Inwoley A, Msellati P, Viho I, Combe P, Leroy V, Dabis F, Rouzioux C: HBV and HCV prevalence and viremia in HIV-positive and HIV-negative pregnant women in Abidjan, Cote d'Ivorie: the ANRS 1236 study. J Med Virol 2004, 74:34-40

76. Adesina O, Oladokun A, Akinyemi O, Adedokun B, Awolude O, Odaibo G, Olaleye D, Adewole I: Human immuno-deficiency virus and hepatitis B virus coinfection in pregnancy at the University College Hospital, Ibadan. Afr J Med Med Sci 2010, 39(4):305-310.

77. Okeke T, Obi S, Okezie O, Ugwu E, Akogu S, Ocheni S, Ezenyeaku C: Coinfection with hepatitis $B$ and $C$ viruses among HIV positive pregnant women in Enugu south east, Nigeria. Niger J Med 2012, 21(1):57-60.
78. Collenberg E, Ouedraogo T, Ganamé J, Fickenscher H, Kynast-Wolf G, Becher H, Kouyaté B, Kräusslich H, Sangaré L, Tebit D: Seroprevalence of six different viruses among pregnant women and blood donors in rural and urban Burkina Faso: a comparative analysis. J Med Virol 2006, 78(5):683-692.

79. Ilboudo D, Karou D, Nadembega W, Savadogo A, Djeneba O, Pignatelli S, Pietra V, Bere A, Simpore J, Traore A: Prevalence of human herpes virus-8 and hepatitis B virus among HIV seropositive pregnant women enrolled in the Mother-to-Child HIV transmission prevention program at Saint Camille Medical Centre in Burkina Faso. Pak J Biol Sci 2007, 10(17):2831-2837.

80. Ouermi D, Simpore J, Belem AM, Sanou DS, Karou DS, Ilboudo D, Bisseye C, Onadja SM, Pietra V, Pignatelli S, Gnoula C, Nikiema JB, Kabre G: Coinfection of Toxoplasma gondii with HBV in HIV-infected and uninfected pregnant women in Burkina Faso. Pak J Biol Sci 2009, 12(17):1188-1193.

81. Dewing S, Plüddemann A, Myers B, Parry C: Review of injection drug use in six African countries: Egypt, Kenya, Mauritius, Nigeria, South Africa and Tanzania. Drugs: Educ Prev Policy 2006, 13(2):121-137.

82. Reid S: Injection drug use, unsafe medical injections, and HIV in Africa: a systematic review. Harm Reduction J 2009, 6:24.

83. Rollins N: Food insecurity: a risk factor for HIV infection. PLoS Med 2007 4:1576-1577.

84. Russell $B$, Easton $L$, Petersen-Williams $P$ : Intersecting epidemics among pregnant women: alcohol use, interpersonal violence, and HIV infection in South Africa. Curr HIV/AIDS Rep 2013, 10(1):103-110.

85. Sellen D, Hadley C: Food insecurity and maternal-to-child transmission of HIV and AIDS in sub-Saharan Africa. Ann Anthropological Pract 2011, 35(1):28-49.

86. Ivers L, Cullen K, Freedberg K, Block S, Coates J, Webb P: HIV/AIDS, undernutrition, and food insecurity. Clin Infect Dis 2009, 49:1096-1102.

87. Davies H, Visser J, Tomlinson M, Rotherham-Borus M, LeRoux L, Gissane C: An investigation into the influence of socioeconomic variables on gestational body mass index in pregnant women living in a peri-urban settlement. South Africa. Matern Child Health J 2011, 16(8):1732-1741.

88. Reddi A, Powers M, Thyssen A: HIV/AIDS and food insecurity: deadly syndemic or an opportunity for healthcare synergism in resource-limited settings of sub-Saharan Africa? AIDS 2012, 26:115-117.

89. Dryfuss M, Msamanga G, Spiegelman D, Hunter D, Urassa E, Hertzmark E, Fawzi W: Determinants of low birth weight among HIV-infected pregnant women in Tanzania. Am J Clin Nutr 2001, 74(6):814-826.

90. Fawzi W, Msamanga G, Spiegelman D, Urassa E, McGrath N, Mwakagile D, Antelman G, Mbise R, Herrera G, Kapiga S, Willett W, Hunter D: Randomised trial of effects of vitamin supplements on pregnancy outcomes and T cell counts in HIV-1-infected women in Tanzania. Lancet 1998, 351:1477-1482

91. Kumwenda N, Miotti P, Taha T, Broadhead R, Biggar R, Jackson J, Melikian G, Semba R: Antenatal vitamin A supplementation increases birth weight and decreases anemia among infants born to human immunodeficiency virus-infected women in Malawi. Clinical Infectious Disease 2003, 35:618-624.

92. Semba R, Chiphangwi J, Miotti P, Dallabetta G, Hoover D, Canner J, Saah A: Maternal vitamin A deficiency and mother-to-child transmission of HIV-1. Lancet 1994, 343(8913):1593-1597.

93. Degarege A, Legesse M, Medhin G, Animut A, Erko B: Malaria and related outcomes in patients with intestinal helminths: a cross-sectional study. BMC Infect Dis 2012, 12:291.

94. Adegnika A, Kremsner P: Epidemiology of malaria and helminth interaction: a review from 2001 to 2011. Curr Opin HIV AIDS 2012, 7(3):221-224.

95. Egwunyenga A, Ajayi J, Nmorsi O, Duhlinska-Popova D: Plasmodium/ intestinal helminth coinfections among pregnant Nigerian Women. Mem Inst Oswaldo Cruz 2001, 96(8):1055-1059.

96. Mwangi T, Bethony J, Brooker S: Malaria and helminth interaction in humans: an epidemiological viewpoint. Ann Trop Med Parasitol 2006 100:551-570.

97. Yazdanbakhsh M, van der Biggelaar A, Maizels R: Th2 responses without atopy: immunoregulation in chronic helminth infections and reduced allergic disease. Trends Immunol 2001, 22:373-377.

98. Mwatha J, Jones F, Mohamed G, Naus C, Riley E, Butterworth A, Kimani G, Kariuki C, Ouma J, Koech D, Dunne D: Associations between anti-Schistosoma mansoni and anti-Plasmodium falciparum antibody responses and hepatosplenomegaly, in Kenyan schoolchildren. J Infect Dis 2003, 187(8):1337-1341.

99. Wickaramsuriya G: Clinical Features of Malaria in Pregnancy: Malaria and Ankylostomiasis in Pregnant Women. London: Oxford University Press; 1937.

100. Yatich N, Jolly P, Funkhouser E, Agbenyega T, Rayner J, Ehiri J, Turpin A, Stiles J, Ellis W, Jiang Y, Williams J: The effect of malaria and intestinal 
helminth coinfection on birth outcomes in Kumasi, Ghana. Am J Trop Med Hyg 2010, 82(1):28-34.

101. Hiller S, Booth M, Muhangi L, Nkurunziza P, Khihembo M, Kakande M, Sewankambo M, Kizindo R, Kizza M, Muwanga M, Bambury M, Elliot A: Plasmodium falciparum and helminth coinfection in a semi-urban population of pregnant women in Uganda. J Infect Dis 2008, 198(6):920-927.

102. Ivan E, Crowther N, Rucogoza A, Osuwat L, Munyazesa E, Mutimura E, Njunwa K, Zambezi K, Grobusch M: Malaria and helminthic coinfection among HIVpositive pregnant women: prevalence and effects of antiretroviral therapy. Acta Trop 2012, 124(3):179-184.

103. Jeon C, Murray M: Diabetes mellitus increases the risk of active tuberculosis: a systematic review of 13 observational studies. PLoS Med 2008, 5(7):e152.

104. Faurholt-Jepsen D, Range N, Praygod G, Jeremiah K, Faurholt-Jepsen M, Aabye M, Changalucha J, Christensen D, Grewal H, Martinussen T, Krarup H, Witte $\mathrm{D}$, Andersen $\mathrm{A}$, Friis $\mathrm{H}$ : Diabetes is a strong predictor of mortality during tuberculosis treatment: a prospective cohort study among tuberculosis patients from Mwanza, Tanzania. Trop Med Int Health 2013, 18(7):822-829.

105. Young F, Critchley J, Johnstone L, Unwin N: A review of co-morbidity between infectious and chronic disease in Sub Saharan Africa: TB and Diabetes Mellitus, HIV and Metabolic Syndrome, and the impact of globalization. Glob Health 2009, 5:9.

106. Mugusi F, Swai A, Alberti K, Melarty G: Increased prevalence of diabetes mellitus in patients with pulmonary tuberculosis in Tanzania. Tubercle 1990, 71(4):271-276.

107. Swai A, McLarty D, Mugusi F: Tuberculosis in diabetic patients in Tanzania. Trop Doct 1990, 20(4):147-150.

108. Dooley K, Chaisson R: Tuberculosis and diabetes mellitus: convergence of two epidemics. Lancet Infect Dis 2009, 9(12):737-746.

109. Gangopadhyay R, Karoshi M, Keith L: Anemia and pregnancy: a link to maternal chronic diseases. Int J Gynaecol Obstet 2011, 115(Suppl 1):S11-15.

110. Dim C, Okafor C, Ikeme A, Anyahie B: Diabetes mellitus in pregnancy: an update on the current classification and management. Niger Journal of Medicine 2012, 21(4):371-376.

111. Hall V, Thomsen RW, Henriksen O, Lohse N: Diabetes in Sub Saharan Africa 1999-2011: epidemiology and public health implications. A systematic review. BMC Public Health 2011, 11:564.

112. Seyoum B, Kiros K, Haileselase T, Leole A: Prevalence of gestational diabetes mellitus in rural pregnant mothers in northern Ethiopia. Diabetes Res Clin Pract 1999, 46(3):247-251.

113. Laraia B, Siega-Riz A, Gundersen C: Household food insecurity is associated with self-reported pregravid weight status, gestational weight gain, and pregnancy complications. J Am Diet Assoc 2010, 110(5):692-701.

114. Ray S, Madzimbamuto F, Fonn S: Activism: working to reduce maternal mortality through civil society and health professional alliances in sub-Saharan Africa. Reprod Health Matters 2012, 20(39):40-49.

doi:10.1186/2049-9957-2-26

Cite this article as: Singer: Development, coinfection, and the syndemics of pregnancy in Sub-Saharan Africa. Infectious Diseases of poverty 2013 2:26.

\section{Submit your next manuscript to BioMed Central and take full advantage of:}

- Convenient online submission

- Thorough peer review

- No space constraints or color figure charges

- Immediate publication on acceptance

- Inclusion in PubMed, CAS, Scopus and Google Scholar

- Research which is freely available for redistribution 